\title{
Première of a partnership: European Headache Federation and The Journal of Headache and Pain
}

Researchers show an essentially ambivalent attitude towards publishing innovations and the headache community is not immune to this behaviour. This has been proven by our high consideration of published works in the headache field appearing every once in a while in generalist, wide-ranging journals with a very high Impact Factor, and to consequent acclaim; compared to our initial indifference towards new sectorial and specialised initiatives. A consolidated publishing tradition encourages this cultural rooting. But what is tradition? A load-bearing pillar of scientific culture, a fully established scientific authority. However, an important change regarding the diffusion of headache culture has taken place and strong roots gain a foothold in new soils. In order not to repeat what Gustav Mahler said, namely "tradition is just an alibi for the laziest ones", a journal's growth and its marriage with a consolidated and ingrained scientific association must be treated as an additional opportunity to listen to scientific necessities with "new ears", at the same time respecting the cultural tradition from which we come.

The European Headache Federation (EHF) celebrates its 15th birthday this year. This supplement con- tains the contributions of the 8th EHF Congress, in Valencia, its greatest success in terms of attendants so far. The very high number of abstracts and their intrinsic quality demonstrate the EHF's success.

The Journal of Headache and Pain is now in its 7th year of life and is experiencing a significant phase of growth, according to both readership and content value.

The Congress proceedings published in The Journal of Headache and Pain represent for us an important reason for pride. Since 1 January 2006 The Journal of Headache and Pain has been the official EHF journal, this joint venture representing the "coming out" into scientific society, the debutantes' ball.

The opportunities developing on this basis come from an increased sense of belonging to the EHF by its own affiliates, who can now take advantage of a stage shared by the various nations confederated into the EHF. Nations more scientifically and historically advanced will partake in these occasions, as well as those countries that are now seeing a growth in scientific interest towards headache medicine.

Therefore, it is with great pleasure that we present this Supplement and invite the Authors of the many 
contributions to submit their manuscripts per extenso to The Journal of Headache and Pain in order to facilitate a fast peer reviewing process of the data now presented exclusively as abstracts.

P. Martelletti Editor-in-Chief of The Journal of Headache and Pain Department of Medical Sciences, 2nd School of Medicine, University La Sapienza, Sant'Andrea Hospital, Via di Grottarossa 1035, I-00161 Rome, Italy e-mail: paolo.martelletti@uniromal.it

Tel.: +39-06-3377-5250

Fax: +39-06-3377-5323
We hope that this journal becomes the permanent "scientific house" for the EHF Congress attendants, bringing headache culture to all headache scientists, new and old, working in European countries. President of the European Headache Federation Department of Neurology, Hospital Clínico Universitario, University of Valencia, Avenida Blasco Ibañez 17, ES-46010 Valencia, Spain e-mail: jlaineza@meditex.es Tel.: +34-96-3868-863 Fax: +34-96-3900-321 